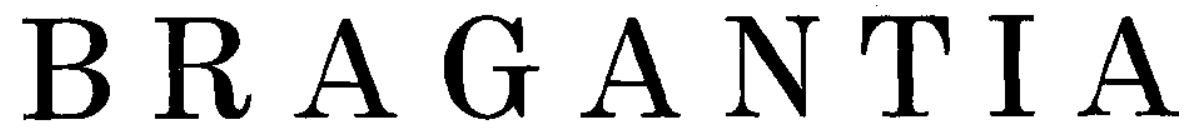

Boletim Técnico do Instituto Agronômico do Estado de São Paulo

Vol. 17

Campinas, dezembro de 1958

N.o 15

\title{
ESTUDOS SÔBRE A CONSERVAÇÃO \\ DE SEMENTES
}

$$
\text { III } \rightarrow \text { TRIGO }\left(^{*}\right)
$$

Oswaldo Bacchy

Engenheiro-agrônomo, Laboratório de Sementes, Seção de Fisiologia,

Instituto Agronômico

\section{RESUMO}

Sementes de trigo, recém-colhidas e contendo diferentes teores de umidade foram conservadas em ambientes hermèticamente fechados e periòdicamente submetidas a testes de germinoção e umidade.

À temperatura não controloda do laboratório, cuja oscilaçāo foi de $12^{\circ} \mathrm{C}$ a $30^{\circ} \mathrm{C}$, observou-se que as sementes com $7,8 \%, 9,2 \%$ e $11,1 \%$ de umidade conservaram-se com poder germinativo superior a $92 \%$ até o final do ensaio, ou seja, durante 30 meses.

Com um teor de umidade de $13,1 \%$, a vitalidade das sementes foi sensivelmente prejudicada a partir do décimo-segundo mês, enquanto que, com $15,2 \%$ de umidade, em apenas dois meses de armazenamento reduziu-se a capacidade germinativa das sementes para $64 \%$.

Armazenadas em ambiente aberto (saco de pano), os sementes já apresentovom $80 \%$ de germinaçõo após seis e oito meses, respectivamente. Nestas condiçōes de armazenamento, a porcentagem de umidade nas sementes sofreu, por sua vez, contínuas alteraçōes, cujos limites máximo e mínimo foram de $15,9 \%$ e $10,5 \%$, num período de 12 meses.

\section{1 - INTRODUÇÃO}

Independentemente dos fatôres hereditários inerentes à própria planta, a longevidade das sementes está sujeita, como se sabe, à ação conjunta de vários fatôres externos, dentre os quais a umidade e a temperatura são, indiscutivelmente, os mais importantes.

Conforme se verifica pela literatura relativamente extensa sôbre o assunto, com exceção de um pequeno grupo de sementes, cuja vitalidade é sensivelmente prejudicada pelo desidratação, as condições de umidade e temperatura baixas são as mais favoráveis para o armaze-

(*) Recebido para publicação em 24 de janeiro de 1958. 
namento da grande maioria das sementes. Por outro lado, qualquer semente armazenada em condições de umidade e temperatura elevadas está sujeita a uma redução em sua longevidade, que será tanto maior quanto mais altas forem aquelas.

Em vista do alto poder higroscópico das sementes, do qual resulta um equilíbrio constante entre o seu conteúdo de água e a umidade relativa do ar ambiente, torna-se evidente a influência decisiva das condições climáticas, inclusive as determinadas pelas estações do ano, sôbre a vitalidade das sementes, quer por ocasião de sua formação e colheita, como durante o seu armazenamento.

Com relação ao problema de conservação de sementes para fins de plantio, a cultura do trigo no Estado de São Paulo está entre aquelas que maiores dificuldades oferecem, pois que, sendo uma cultura de inverno, suas sementes necessitam ser guardadas durante os meses de setembro a fevereiro, que são, normalmente, os menos favoráveis para êsse fim, tanto no que diz respeito à umidade como à temperatura.

Daí, pois, o motivo da realização do ensaio de laboratório que ora é apresentado neste trabalho, cujo objetivo foi o de obter alguns esclarecimentos a respeito desta importante questão.

\section{2 - MATERIAL E MÉTODOS}

O ensaio foi realizado com sementes provenientes de São Bento do Sapucaí, da colheita de 1949 e fornecidas pela Seção de Cereais dêste Instituto. São da variedade Garnet - 63 (Triticum aestivum L.), a qual na ocasião estava incluída entre as que tinham possibilidades de ser introduzidas na triticultura paulista.

Feitas as determinações iniciais das porcentagens de umidade e de germinação, cêrca de $1500 \mathrm{~g}$ de sementes recém-colhidas foram devidamente homogeneizadas e separadas em seis porções iguais, uma das quais, sem sofrer qualquer alteração no seu teor de umidade, foi colocada em um saquinho de pano (recipiente "aberto") e conservada no ambiente do laboratório.

Ao mesmo tempo, com o objetivo de obter lotes de sementes com diferentes teores de umidade, três das cinco porções restantes foram imediatamente desidratadas em estufa à temperatura de $30-40^{\circ} \mathrm{C}$; outra porção foi hidratada por meio de pulverizações com água e a última, conservada com a mesma umidade inicial. Em seguida, todos 


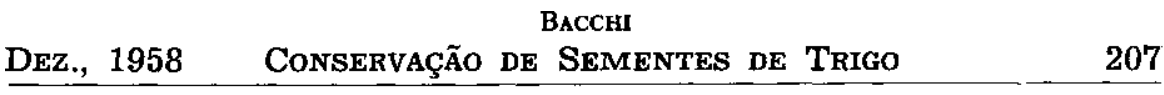

êsses lotes foram colocados em recipientes hermèticamente fechados, onde permaneceram oito dias para a uniformização da umidade.

Após êsse periodo, durante o qual as sementes foram frequientemente agitadas, cada um dêsses cinco lotes foi subdividido em dez amostras de 300 sementes cada e mais duas de $20 \mathrm{~g}$; estas amostras foram hermèticamente fechadas em pequenos tubos de vidro e conservadas à temperatura do laboratório, para posteriores observações periódicas. Nessa mesma ocasião também se determinaram as porcentagens de umidade e germinação, que seriam as iniciais de cada um dêsses lotes.

Tôdas as determinações de umidade foram feitas sem repetição, em amostras de $20 \mathrm{~g}$ de sementes não moídas, mediante desidratação em estufa sem ventilação forçada, à temperatura de $105^{\circ} \mathrm{C}$, durante 48 horas. As porcentagens foram calculadas na base do pêso úmido.

Os testes de germinação foram realizados pelo sistema de rôlo de pano e em germinadores à temperatura ambiente, usando-se três amostras, cada uma de 100 sementes.

\section{3 - RESULTADOS}

Os dados das determinações periódicas de umidade e germinoçõo, referentes às sementes armazenadas nos diferentes ambientes, acham-se reunidos no quadro $l$ e gràficamente representados na figura 1 .

As sementes contendo $7,8 \%, 9,2 \%$ e $11,1 \%$ de umidade e conservadas em ambiente hermèticamente fechado não mostraram, durante tôda a duração do ensaio, qualquer sinal de perda de vitalidade; após os 30 meses de armazenamento estas ainda apresentavam, respectivamente, $96 \%, 95 \%$ e $92 \%$ de germinação.

Nesse mesmo ambiente fechado, as sementes com o teor de umidade natural de $13,1 \%$ conservaram-se muito bem até o décimosegundo mês; a partir dai, a perda de vitalidade foi sensível, chegando a $0 \%$ de germinação no final do ensaio.

As sementes armazenadas em ambiente fechado, com $15,2 \%$ de umidade, sofreram uma queda imediata em sua capacidade germinativa, atingindo o índice bastante baixo de $64 \%$ em apenas dois meses, e de $11 \%$ no final do sexto mês. 


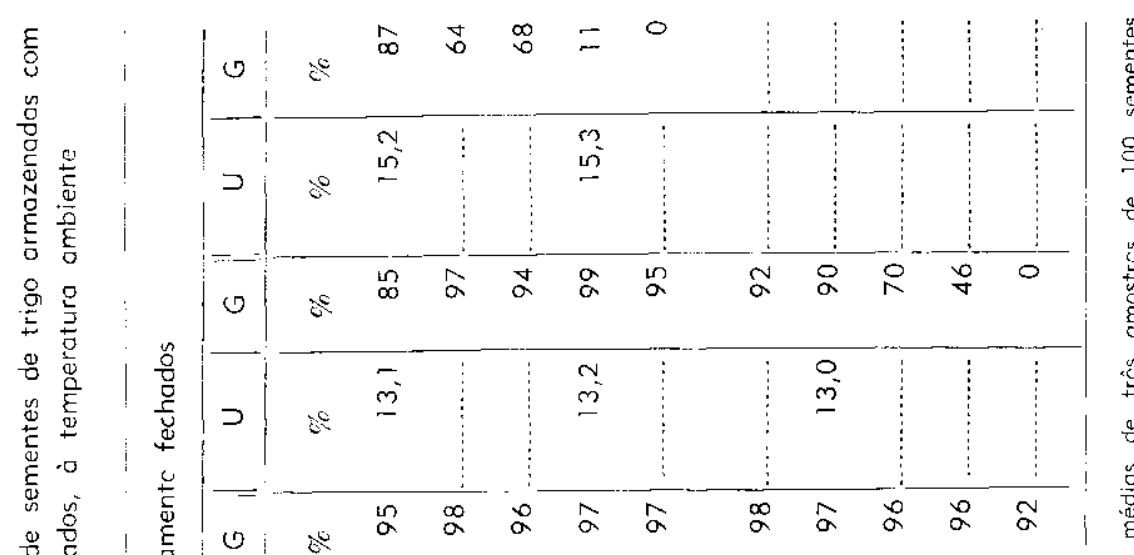




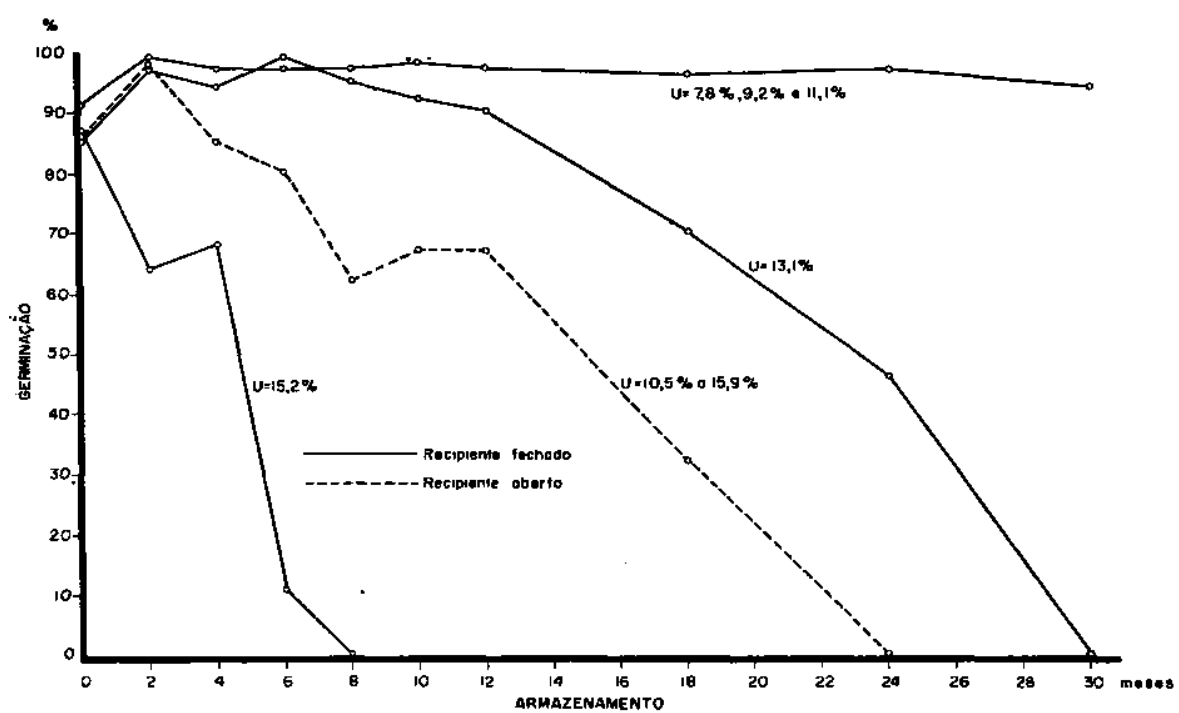

Figura 1. - Poder germinativo de sementes armazenadas com diferentes teores de umidade.

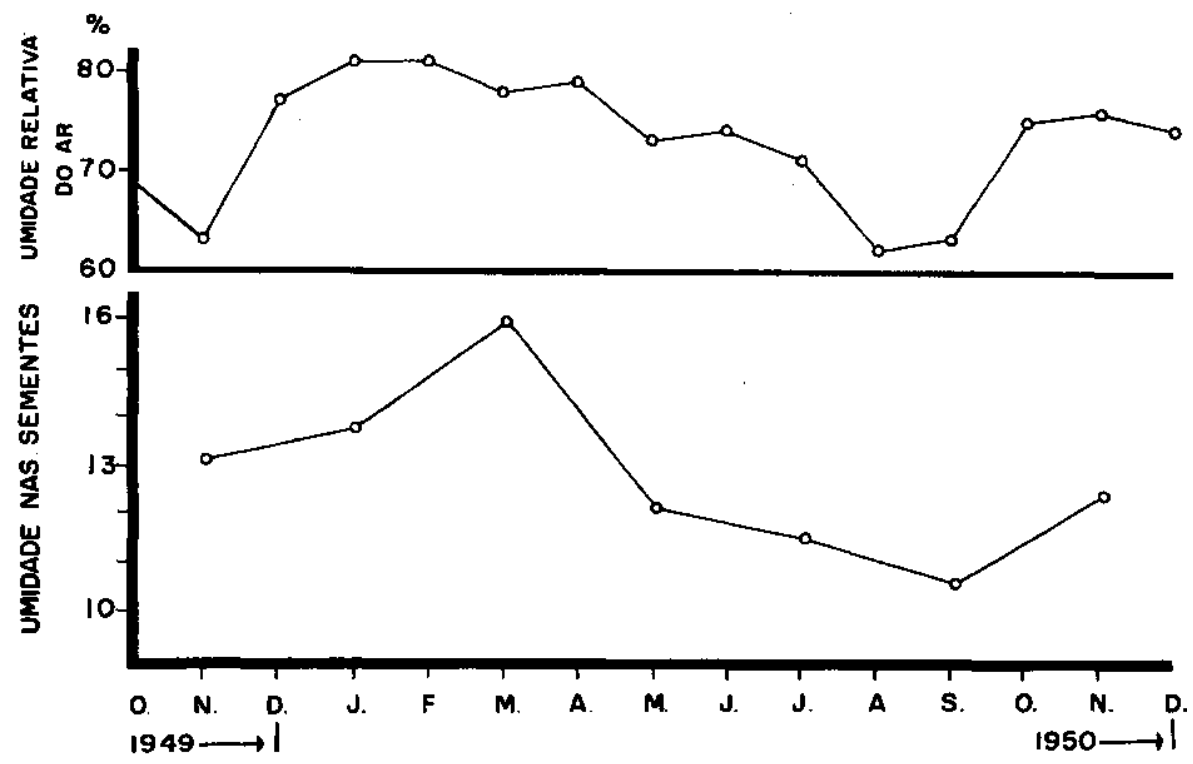

FrgurA 2. - Oscilação da umidade contida nos sementes. e sua relação com a umidade relativa do ar, de outubro de 1949 a dezembro de 1950 . 
Pelas determinações feitas após 8 e 12 meses, verifica-se que as sementes colocadas em ambiente hermèticamente fechado conservaram-se, como era desejado, com os mesmos teores iniciais de umidade. Por outro lado, a porcentagem de umidade nas sementes armazenadas em ambiente aberto (saco de pano) sofreu, no período de um ano, alterações relativamente grandes, que aproximadamente acompanham as flutuações mensais da umidade relativa do ar ambiente. Conforme se observa pela figura 2, essas alterações atingiram o limite máximo de $15,9 \%$ no decorrer do quarto mês, ou seja, no mês de março, que corresponde ao final do período chuvoso; o limite mínimo de 10,5\% verificou-se, por sua vez, após 10 meses de armazenamento, isto é, no fim do mês de setembro, que é, normalmente, a época do ano em que a umidade relativa do ar alcança os valores mais baixos.

Como consequiência provável dessas contínuas alterações de umidade, as sementes guardadas em ambiente aberto, com o teor de umidade inicial de $13,1 \%$, com apenas quatro meses de armazenamento começaram a mostrar indícios de enfraquecimento na sua vitalidade e, no final do oitavo mês, com uma porcentagem de germinação de $62 \%$, já podiam ser consideradas pouco recomendáveis para plantio.

Durante a realização do ensaio a temperatura ambiente oscilou entre $12^{\circ} \mathrm{C}$ a $30^{\circ} \mathrm{C}$.

\section{4 - DISCUSSÃO E CONCLUSÕES}

Robertson e outros (5), investigando o efeito da umidade relativa do ar sôbre a vitalidade das sementes de trigo, aveia e cevada em armazenamento, concluem que a umidade do ar ou da semente, pode ser usada como índice estimativo da longevidade da semente. Assim, sementes dessas plantas, contendo mais de $20 \%$ de umidade (pêso sêco), estão condenadas a perder sua vitalidade em menos de um mês, ao passo que, com $10 \%$, essas sementes podem manter sua capacidade germinativa pelo espaço aproximado de três anos.

Segundo Robertson e outros (6), sementes de trigo armazenadas em sacos, no clima árido de Fort Collins, Colorado, U.S.A., conservaram, durante 10 anos, cêrca de $95 \%$ de sua capacidade germinativa inicial; em 15 anos, aproximadamente $72 \%$ e em 21 anos, uma média de $13 \%$. Os autores não fazem, entretanto, qualquer referência à 
porcentagem de umidade nas sementes; apenas informam que a umidade relativa do ar foi bastante baixa durante todos êsses anos.

De acôrdo com Kaihara, citado por Owen (4), sementes de trigo com um teor de umidade de $12 \%$, apresentaram, após 33 meses de armazenamento em ambiente hermèticamente fechado, $82 \%$ de germinação.

Whymper e Bradley, citados por Owen (4), obtiveram uma germinação de $69 \%$ em sementes de trigo armazenadas durante 32 anos, com um teor de umidade que variou entre $4,5 \%$ e $4,8 \%$.

Dados obtidos por Bailey e Curjar (1) indicam, por outro lado, que as sementes de trigo com um teor de umidade oo redor de $14 \%$ apresentam um quociente respiratório suficiente para comprometer significantemente sua conservação, mormente quando a temperatura ambiente fôr elevada.

Levando-se em conta a influência de outros fatôres, principalmente a temperatura, bem como pequenas diferenças nos dados relativos às porcentagens de umidade motivados pelos diferentes métodos usados em suas determinações, os resultados do ensaio realizado neste Laboratório conduzem a conclusões bastante semelhantes àquelas dos autores citados.

Barton (2) e Lo Pine e Milberg (3) demonstraram que as flutuações periódicas nos teores de umidade das sementes podem ser mais prejudiciais às sementes do que um teor de umidade constante, ainda que êste seja igual ou pouco inferior ao máximo atingido nessas flutuações.

No presente ensaio, a longevidade das sementes conservadas no ambiente aberto, cujos teores de umidade oscilaram entra 10,5\% e $15,9 \%$, foi intermediária entre aquelas verificadas com as sementes que foram hermèticamente fechadas com $13,1 \%$ e $15,2 \%$ de umidade.

\section{THE INFLUENCE OF MOISTURE CONTENT ON THE VIABILITY OF WHEAT SEEDS}

\section{SUMMARY}

Freshly harvested seeds of Garnet-63 wheat (Triticum aestivum L.) were adjusted to four different moisture contents and stored in sealed containers at room temperature.

Germination better than $92 \%$ was obtained ofter seeds containing $7.8,9.2$ and $11.1 \%$ of moisture content were stored during 30 months.

Complete viability for 12 months was obtained for seeds with the natural $13.1 \%$ 
of moisture content; marked decrease in the percentage of germination was observed when those seeds were stored longer.

For stored seeds with $15.2 \%$ of moisture content, the germination was reduced to $64 \%$ after 2 months, and to $0 \% 6$ months later.

Seeds with the natural $13.1 \%$ of moisture content, and stored in open container at room temperature, after 6 and 8 months germinated 80 and $62 \%$ respectively. Under these storage conditions the moisture content of the seeds varied betwen 10.5 and $15.9 \%$ during the 12-month period of the experiment.

\section{LITERATURA CITADA}

1. BAILEY, C. H. \& GURJAR, A. M. Respiration of stored wheat. J. agric. Res. 12:685-713. 1918.

2. BARTON, LELA V. Effect of moisture fluctuotions on the viability of seeds in storage. Contr. Boyce Thomp. Inst. 13:35-45. 1943.

3. LAPINE, L. J. \& MILBERG, E. A study of the effect of moisture on the longevity of imported Chewings fescue seed under laboratory and warehouse conditions. Annual meeting of the Association of Official Seed Analysts, 38th., Springfield, III., 1948. Proceedings. Washington, D. C., Souls Liteograph Co., 1948. p. $62-65$.

4. OWEN, E. B. The storage of seeds for maintenance of viability. Hurley, Berks, Commonwealth Bureau of Pastures and Field Crops, 1956. V, 81 p. (Bull. 43)

5. ROBERTSON, D. W., LUTE, A. M. \& GARDNER, R. Effect of relative humidity on viability, moisture content, and respiration of wheat, oats and barley seed in storage. J. agric. Res. 59:281-291. 1939.

6. —— KROEGER, H. Germination of 20-year-old wheot, oats. borley, corn, rye, sorghum and soybeans. J. Amer. Soc. Agron. 35:786-795. 1943. 